\title{
ARTICLES \\ Genome Editing and Responsible Innovation, Can They Be Reconciled?
}

\author{
Ann Bruce ${ }^{1}$ (D) Donald Bruce ${ }^{2}$
}

Accepted: 2 July 2019 / Published online: 8 July 2019

(c) The Author(s) 2019

\begin{abstract}
Genome editing is revolutionising the field of genetics, which includes novel applications to food animals. Responsible research and innovation (RRI) has been advocated as a way of ensuring that a wider-range of stakeholders and publics are able to engage with new and emerging technologies to inform decision making from their perspectives and values. We posit that genome editing is now proceeding at such a fast rate, and in so many different directions, such as to overwhelm attempts to achieving a more reflective pace. An alternative location for reflection is during the much slower process of taking products from the lab to market. We suggest emphasising Responsible Innovation, putting the 'I' back into RRI, and encouraging companies to embrace an RRI approach. We review some previous attempts at developing industry-relevant frameworks for RRI. We then describe two examples of genome editing in livestock; hornless cattle and disease resistant pigs, and reflect on the sorts of questions that could be considered in these two genome editing examples. This paper seeks to take forward the discussion on RRI by extending it to bringing products to market in the context of genome edited livestock.
\end{abstract}

Keywords Responsible research and innovation - Genome editing · Gene editing · Livestock · Agriculture $\cdot$ Public engagement

\section{Introduction}

Genome editing is an emerging technology which has revolutionised the field of genetics, by providing a far more precise, rapid and cheap way for humans to modify, adapt and use animals, plants and lower organisms, and even to alter their own genome. But the very rapidity of its uptake and the breadth of its scope present a

Ann Bruce

Ann.bruce@ed.ac.uk

1 The University of Edinburgh, Old Surgeons' Hall, High School Yards, Edinburgh, UK

2 Edinethics Ltd., 11/6 Dundonald Street, Edinburgh, UK 
serious policy challenge to the prevailing model of responsible research and innovation (RRI). RRI has been described by the European Commission as "an approach that anticipates and assesses potential implications and societal expectations with regard to research and innovation, with the aim to foster the design of inclusive and sustainable research and innovation". It has come to represent a greater emphasis on upstream, stakeholder and public engagement on novel technologies, in the wake of the 1999 genetically modified food crisis. But the very speed and breadth of the scientific development of genome editing presents a context in which appropriate public understanding and ethical reflection of the technology become difficult.

In this paper we explore the tensions between responsible innovation and developments in genome editing applied to livestock animal applications for food. This field had largely lain outwith the scope of earlier genetic modification techniques, but has emerged as a likely early commercial uptake of genome editing. It is timely to consider these questions because the range of potential applications of genome editing is growing rapidly, and some are at an advanced stage of development.

Decisions made about the governance of genome editing at this early stage are likely to have major impacts on future developments. Such decisions have the potential either to 'strangle at birth' ideas that in retrospect prove to have been important, or on the other hand to enable applications which are later regretted, often due to adverse unintended consequences. Thus it is important to explore how a responsible innovation pathway can be navigated through these challenges.

This paper is drawn from and informed by our long-standing experience in the ethical and social dimensions of the application of genetics to agriculture, and our engagement with both research and industrial contexts and with experts, stakeholders and publics, beginning in 1993 with one of the first studies on the ethics of genetic engineering technologies to micro-organisms, plants and animals (Bruce and Bruce 1998), through to ongoing current research on genome editing ethics. One of us (Bruce, A.) researches in innovation studies in agriculture, including public and stakeholder discussions, and formerly worked in commercial pig genetics. The other (Bruce, D.) has performed extensive ethical studies over 25 years in biotechnology and nanotechnology, and developed tools for public engagement in several of these fields. While we reflect a primarily UK perspective on the questions, this is set in the wider European discussions on the role of responsible research and innovation, and of the current and historic influence that the European Union (EU) policies have had on the UK.

The paper is structured as follows. First we reflect on what is understood by responsible research and innovation in the impetus to make science more democratic and accountable, and in the wake of adverse public reactions to Genetically Modified (GM) crops. We then consider the developments in genome editing, in particular following the introduction of CRISPR-Cas9 technology, and highlight two potentially near-market applications in dairy cattle and pigs. We assess the challenge to RRI that rapid expansion and enormous scope of genome editing at the research stage presents, the potential of RRI in the much slower process of bringing an innovation to market, and the neglected application of RRI to industry. Finally, we return to the two genome editing examples and reflect on the sorts of issues which an RRI 
approach would need to consider in relation to these innovations to relate them to wider society, and on the importance that such a process is indeed performed.

\section{About RRI}

Responsible research and innovation (RRI) emerged as a concept in the early 2000s, as a response by the European Commission (EC) to the governance challenges first posed to regulation by GM crops, of needing to relate new scientific developments, such as embryonic stem cells, nanotechnologies, synthetic biology and geoengineering, to society. It may be seen as a way to articulate and apply the notion that technological innovation should not just be the activity of the principal players of science, industry and government, with the general public merely in the role of recipient consumers, whose only engagement is whether they do or do not buy the resulting products. The RRI concept sets out that publics should be given the opportunity to engage and interact with the proposed innovations as citizens in a collaborative exercise of decision making. It embodies the assumption that there may be valid values, concerns and insights, when seen from other perspectives than just those of the promoters of a technology, and which need to be given due consideration in policy making. A focal implication of RRI is that, if it can be articulated sufficiently cogently, the 'wisdom' of the wider culture should have at least some power to change what 'the usual players' would otherwise have done with their innovation, if left to their own devices.

The notion of responsibility in innovation can be traced far back in the history of technology (Mitcham and von Schomberg 2000), moving from the individual engineer to wider society. In some ways RRI can be seen as a development of an approach that became especially associated with the Human Genome Project, in which Ethical, Legal and Social Issues (ELSI) were addressed at an expert professional level in parallel with the science (Knoppers et al. 2013). RRI tends to set a less dominant role for expert ethical reflection, and places greater emphasis on lay public and stakeholder engagement and its analysis by social science methods. Ribeiro observes that RRI could be viewed as "the latest manifestation in a long line of policy-oriented debates concerned with providing space to consider and debate the interactions between the oft-separated worlds of 'science' and 'society", (Ribeiro et al. 2017: 84).

RRI is a multi-dimensional concept which can be described in many ways. Von Schomberg summarises it as "RRI should be understood as a strategy of stakeholders to become mutually responsive to each other and anticipate research and innovation outcomes underpinning the 'grand challenges' of our time for which they share responsibility", which implies "broader foresight and impact assessments for new technologies beyond their anticipated market-benefits and risks." (von Schomberg 2013). RRI reflects variously the desire to avoid unintended consequences, to align innovation to societal expectations and to democratise science by opening it up to wider debate, particularly when science challenges basic values (Ribeiro et al. 2017). 
The approach was adopted by the EC both as a key action and a cross-cutting issue in the Horizon 2020 research programme, with the expectation that "societal actors (researchers, citizens, policy makers, business, third sector organisations etc.) work together during the whole research and innovation process in order to better align both the process and its outcomes with the values, needs and expectations of society". ${ }^{1}$

The UK Engineering and Physical Sciences Research Council (EPSRC) has formalised the approach into a framework for Responsible Innovation that "seeks to promote creativity and opportunities for science and innovation that are socially desirable and undertaken in the public interest". Furthermore "Responsible innovation creates spaces and processes to explore these aspects of innovation in an open, inclusive and timely way"2 (our emphasis).

The EPSRC's framework, for example, advocates an approach that encompasses anticipation, reflection, engagement and action, as follows. Anticipation involves describing and analysing impacts (intended or otherwise). Reflection requires thinking about the purposes, motivation, uncertainties, ignorance, assumptions, framings and social transformations entailed. Engagement involves opening up visions for broader deliberation. Finally, Action uses the above processes to influence decisions. The EPSRC also acknowledges that no single approach is appropriate for all applications, and therefore requires researchers to have demonstrated their awareness and commitment to these key steps, in ways appropriate to their activity.

These four criteria in EPSRC's framework broadly echo four core dimensions (anticipation, reflexivity, inclusion and responsiveness) that are identified widely in literature (e.g. Stilgoe et al. 2013; Burget et al. 2017). Several other dimensions are also noted, namely transparency (Pellé 2016), trust (Asveld et al. 2015), sustainability and care (Burget et al. 2017). The term 'Care' is used here as a way of capturing the need to take responsibility for the effects of technological developments. RRI thus seeks to bring together ideas found variously in technology assessment, ELSI and public engagement.

Another feature of RRI in some understandings is in providing socially desirable innovations. In this approach, some advocate switching the typical presentation of an innovation as a solution to a problem to asking first what is the problem, and then considering all the different ways of approaching answering it, including the proposed novel technology. In practice, matters may be more complex. A problem may have reached stalemate, and is only highlighted again when an innovator spots an opportunity to apply their technology to it. The question then needs to be asked if this is indeed the best solution to the problem. It is thus a more iterative process, looking from both sides, which is indeed a role for RRI.

At the same time as advocating an RRI approach, the UK Government and EU both strongly emphasise the role of science for the purpose of economic growth and the generation of employment opportunities. The relationship between research and

\footnotetext{
1 https://ec.europa.eu/programmes/horizon2020/en/h2020-section/responsible-research-innovation accessed 24/11/18.

${ }^{2}$ https://epsrc.ukri.org/index.cfm/research/framework/accessed 2/5/18.
} 
industrial application is considered very important. Tait, however, notes that RRI has tended to focus more on responsible research than responsible innovation (Tait 2017). Given that an impetus for RRI was the societal resistance to genetically modified organisms (GMOs) in the EU, and that at least part of the resistance was the dominance of multinational companies in the production of GMOs, it would be of concern if RRI was failing to address the critical industrial and commercial context by which innovations come to market.

Here the context for RRI is different. The competitive element of commercial enterprise is not to be first to publish but to establish a market, often over their competitors' rival products, and to maintain share price and reputation. New spin-out companies from academic establishments are particularly vulnerable, often struggling to maintain funding streams until they place their product on the market that is able to maintain the existence of the company though income gained from sales. The need to bridge this gap between research funding and commercial income (often referred to as the 'valley of death') means there is an urgency to getting products onto the market. The relation of these factors to RRI is discussed further in "Putting the 'I' Back into RRI" section.

\section{Genome Editing in Livestock Animals}

Genome editing has emerged following the development of a set of powerful scientific tools potentially capable of making a wide range of changes in the DNA of plants, animals and perhaps even human embryos. In particular, the development of the CRISPR-Cas9 technique has provided a cheap, easy to perform and remarkably precise technique to cut the DNA at a chosen location, and then to delete, replace or insert specific genetic material. Whereas the genetic modification methods pioneered in the 1980s and 1990s tended to perform random insertions, from which the desired ones were selected, CRISPR and its related genome editing techniques achieve something like the precision which was claimed for GM, but not really delivered.

The introduction of genome editing tools in the early 2000s has transformed the prospects for manipulating DNA. A suite of tools, including Zinc Finger Nucleases, Transcription Activator-like effector nucleases (TALENS) and, most recently Clustered Regularly Interspaced Short Palidromic Repeats (CRISPR) offer the promise of precision cutting of DNA with enzymes (some of which, such as CRISPR are part of the natural immune defence mechanism of bacteria). They can introduce changes either by spontaneous mutation due to inaccuracies in the resulting DNA repair, or more precisely, by providing a donor template to introduce the desired change (e.g. Ruan et al. 2017). While gene variants present in other species may be introduced (the introduction of so-called transgenes), the technique also allows modification of single nucleotides, representing variants present in another breed of the same species (e.g. Carlson et al. 2016). This relative ease of use of CRISPR has opened up multiple opportunities in a wide-range of applications for use of this technology.

The precision of genome editing has been challenged on the basis of the existence of off-site effects, where changes in the DNA occur in places other than the area 
targeted. These effects continue to stimulate debate and their importance remains controversial. Some advocate that they cannot be completely eliminated, yet others suggest they only rarely occur, and techniques for reducing their incidence or for removing them have been mooted.

To date, genome editing has been applied at an experimental level to several livestock species in a number of different applications. Examples are increased resistance to cattle diseases (e.g. Wu et al. 2015), producing more muscle in otherwise very un-muscled varieties of cattle and sheep (e.g. Proudfoot et al. 2015), and eggs with reduced allergenicity (COGEM 2017; Hoyos-Flight et al. 2017 quoting work by Tim Doran). In this paper, we consider the two most advanced applications, namely the production of dairy cows which do not develop horns, known as polled cows (Carlson et al. 2016), and pigs resistant to a serious but common disease, Porcine Reproductive and Respiratory Syndrome (PRRS) (Whitworth et al. 2016; Burkard et al. 2017).

In the first of these, the presence or absence of horns is controlled by variations or mutations in a single gene, although the exact nature of the variation can differ among breeds. Polled dairy cows do exist, but they are rare. However, polled variants exist more commonly in other cattle breeds, such as Aberdeen Angus. In the example reported by Carlson et al. (2016), genome editing techniques have been used to introduce a gene variant from Aberdeen Angus into a Holstein dairy breed of cow, resulting in a polled dairy cow (see also Eriksson et al. 2018).

It is argued that genome editing will allow the introduction of the desired characteristic directly into elite dairy cows, rapidly and without losing any other desirable characteristics. Mulder has estimated that using genome editing the polled characteristic could be made predominant in dairy cattle within 2-5 generations (COGEM 2017) whereas it could take 20-30 years to do so by traditional means (Bastiaansen et al. 2018). The stated motivation is to benefit both animal and human welfare.

The second example is to use genome editing in pigs to induce resistance to Porcine Reproductive and Respiratory Syndrome (PRRS). PRRS is a widely occurring pig disease around the world, causing reproductive losses and deaths of young piglets. From an economic point of view, PRRS can cause serious economic damage to an industry that at times is working with small margins between profit and loss. It affects both pigs kept indoors and those kept outdoors. The virus exists in different strains. The US has a more serious strain than in Europe. In the UK, PRRS infection can be controlled to some extent by vaccination, however the process of vaccination does require handling and injecting the pigs and it can be costly.

Two versions of genome editing to produce resistance to PRRS in pigs have been reported in the scientific literature. The first report (Whitworth et al. 2016) produced a complete removal of the gene CD163, whereas the second (Burkard et al. 2017) has only removed a portion of the gene that is required for infection. A question remains as to what are the functions of this gene other than its effect on disease. Removing only a part of the gene is less likely to affect other aspects of the pig's physiology than removing the whole gene. ${ }^{3}$ Both developments have been made in

\footnotetext{
3 Bruce Whitelaw, personal communication.
} 
collaboration with a major international pig breeding company (Genus plc) which now seeks to take the products through the FDA regulatory system, with a view to having products in the market within a few years (Genus 2015).

We highlight these as examples of considerable scientific and increasing commercial interest in using genome editing as a way of altering the genetic make-up of livestock. We note also that much of the emphasis has been on welfare issues which affect production, rather than purely improving productivity.

\section{Genome Editing as a Challenge to Responsible Research and Innovation}

From a scientific point of view, genome editing is a very exciting innovation, whose apparently boundless prospects have activated scientists all over the world in many different fields to apply the techniques to areas both old and new. Its development has become not the disciplined flow of a limited number of research groups, but rather an avalanche of applications, spreading rapidly and chaotically. A search in Web of Science found 139 papers referring to CRISPR in 2010-2011, increasing to 5809 in 2016-2017. In that time period, the number referring to a livestock species increased from two to around 140, although not all referring to agricultural applications. It is hard even for specialists and policy makers to keep pace with developments, some of which may have far-reaching social and ethical implications. How then can wider society make any meaningful engagement or have a say in something that is happening so fast within the confines of the scientific community, with which it is not normally engaged? We suggest that the speed, the breadth of scope and the disruptive potential of genome editing together present a serious challenge to the very concept of socially responsible research and innovation.

In such a rapidly moving and novel scientific field, the predominant values are apt to be those underlying innovation and curiosity, and the drive to be first in the field, in preference to wider ethical, social and environmental considerations. The pressure on time to be the first to publish, to patent, or to market operates in opposition to the idea of a relaxed timescale sufficient for wider society to evaluate developments and express a view about them.

A responsible scientist may have given much thought to the implications of his or her work, and will have lived with it for some considerable time. To other stakeholders and the wider public, however, it may be a completely novel and surprising idea, which they need to take time to assimilate, understand and evaluate. For a development to be considered responsibly by wider publics, it is not simply a matter of informing the public and then inserting a quick 'ethics' step in the process of forwarding the innovation. Even once people have had the opportunity to learn about the piece of work, ethical reflection on an unfamiliar and perhaps challenging topic inevitably takes much longer.

A single exercise in 'public engagement' is not sufficient. At best this can only represent a lay person's short-term response to the novel field. It can take a much longer time to consider the merits or otherwise of a disruptive idea against one's personal set of values and view of the world. If the people engaged continue to 
reflect upon it over the next few months, their views will mature and may change. Studies engaging publics should seek to return to the participants perhaps a year after the main engagement, and ask them how their views have developed, and what they think about what has happened in the field in the intervening 12 months.

Moreover, most public engagement exercises will involve, at best, a few hundred people out of a population of millions, leaving wider society so far unengaged. Only once the media or social media pick up an issue does a much wider constituency of people normally begin to think about it. This has the advantage of wider discussion, but carries the disadvantage that, instead of a carefully planned and informed deliberative exercise, the topic is then framed by what the media think 'makes a good story'. This is often accompanied by 'sound bytes', or journalistic tropes, which may deflect the issue on to simplistic or unhelpful ways of thinking, or occasionally even false concepts, such as the connotations engendered in the public mind by the repetition of the slogan 'Frankenstein foods' in the GM food debate.

Prominent among the media tropes are an adversarial two-way conflict, and the need to present both sides of the argument with apparent equal weight, which may mislead if the argument is multi-dimensional or if a minority scientific view is given an apparent weight far in excess of its validity and support. A newspaper may take a stance of aggressively promoting one side of the case, and 'spin' their reportage to suit their current editorial policy. Thus the citizen's deliberation is apt to be confused by what is reported of the conflicting claims and disputed evidence of the major stakeholders, without having the background to weigh up the claims. In social media, importance may be given to a particular person whose comments and opinions one 'follows' but whose knowledge and experience of the subject may be only limited and, in reality, unable to bear the weight of trust put upon them. Someone may be trusted by not trustworthy (O'Neill 2018).

If left to a media process alone, the risk is that, heard through the lens of a polarised framing of the issues, publics may simply reject an innovation if it appears too disruptive or uncertain, when they might have reacted differently if it had proceeded at a pace sufficient to allow public deliberation. One hope of RRI is that upstream engagement would provide such a process of deliberation to happen. However, no effective process has yet been found to disseminate small scale exercises, such as citizen's juries, to the population at large, especially when the issue may not loom large in a given person's matters of current concern.

A further question is, when is the right time to engage with publics about a novel scientific development. In the case of genetically modified crops it was far too late, but it can also be too early. Public engagement needs to be grounded in what is realistically possible, and what are the various options available rather than ask questions in an imaginary future context in which things that may be impossible are postulated to happen, and applications that do eventually come to fruition are missed. Nanotechnology was identified as the next new technology ripe for upstream engagement, wishing to avoid a repeat of the GM situation (Gavelin et al. 2007). A series of different public engagements was conducted, but in retrospect, the subject 'nanotechnology' was too broad and had insufficient examples of applications to provide focus. The publics' responses were broad generalities about preferred directions of research, which added little useful in the way of insights for policy makers 
to guide the development. In contrast, an exercise by the EPSRC presented a set of clear potential medical applications of nanotechnology as future research themes, to which publics responded with some significant observations of factors which had been not considered by the scientists (Bhattachary et al. 2008).

Some research groups and institutes do indeed seek to engage people in their locality on their genome editing research. The need for a responsible innovation approach to genome editing has been recognised by research scientists, including the setting up of a European Steering Committee to address these issues (Chneiweiss et al. 2017). In the UK, lay members are appointed to some scientific and ethical advisory committees, such as in the field of animal research, both at national and local level, where genome editing developments may be considered. In practice, it can be hard for a truly lay person to engage effectively with the wider implications of, say, a highly technical research proposal. A measure of understanding of the field is often needed, so that the 'lay' person becomes to some extent normalised to the alignment of the institution or research council, and no longer providing an entirely non-aligned viewpoint. Notwithstanding such involvement, in the main, publics have relatively little influence on the priorities and research plans of the institute, or interaction with the direction of research priorities set by the main funding agencies. This represents an Achilles heel in RRI, since scientists need to be answerable to their funders, but this tends to be done primarily at the level of review by the peers on funding committees.

At the level of exploratory research into genome editing, it might be argued that the scientific 'genie' is so far out of the bottle that any deliberative engagement with publics is already after the event. Engagement is certainly worth doing in terms of enabling the public to have the opportunity to know what is going on in areas of research which may impact on their lives, and whose funding may well have come from their taxes, but would have little influence on work that is already several years in progress.

We conclude that RRI is probably unrealistic when it comes to genome editing research, in that it would be to try to bring order to an avalanche, because of the unrestrained and chaotic way an exciting new field gets taken up by the research community. Only a few labs among many might be willing and able to do this sort of reflexive exercise and to adapt their research programmes and priorities accordingly.

\section{Putting the 'I' Back into RRI}

A more effective opportunity for applying the concept of RRI to genome editing could lie in the time lag between research which has reached 'proof of principle' stage in the idealised environment of the research laboratory, and the appearance of the refined and thoroughly tested product on the farm, the supermarket shelf or the clinic. There is a usually lengthy and expensive process of developing the conditions needed to commercialise a technique, achieving an adequate size of population, testing against adverse effects, and satisfying the relevant regulatory requirements. Often this can mean complex iterations rather than linear processes. To what extent does this provide an opportunity for engaging with a wider range of stakeholders 
and publics before putting an application to be tested in the market, once there is a concrete product of the research which people could 'get their heads round'? Given the difficulties noted about early upstream engagement on nanotechnologies, when there were few applications for the public to visualise, this would seem a more appropriate moment to apply the RRI concept to genome editing.

Such engagement by industry is not a new idea. For example, in 2000-2001 several US biotechnology companies invited a range of stakeholders, including sceptical NGOs, to a series of meetings to help them draw up an ethical code for genetically modified crop development, in the wake of mounting controversies, hosted by the Center for Bioethics of the University of Pennsylvania. One of the authors represented religious viewpoints in this exercise and also was the only European. The discussions addressed many of the facets of the complex problem, and were frank and open. It did not, however, result at that time in the hoped for industry code.

Fearing a hostile reception to nanotechnologies, the European Commission drew up a Nano Code which was largely aimed at research. A parallel initiative was launched by the Royal Society, the Nanotechnology Industries Association and other bodies to develop a Code for businesses working with nanotechnologies, organised Insight Investment, the Nanotechnology Industries Association and the Nanotechnology Knowledge Transfer Network. The resulting Responsible NanoCode was focused around seven principles that organisations should follow: ${ }^{4}$

- Ensure that responsibility for guiding and managing its involvement with nanotechnologies resides with the Board or governing body;

- Proactively engage with its stakeholders and be responsive to their views in its development or use of products using nanotechnologies;

- Identify and minimise sources of risk for workers handling products using nanotechnologies, at all stages in the production process or in industrial use, to ensure high standards of occupational health and safety;

- Carry out thorough risk assessments and minimise any potential public health, safety and environmental risks relating to its products using nanotechnologies;

- Consider and respond to any social and ethical implications and impacts in the development or sale of products using nanotechnologies;

- Adopt responsible practice in the sales and marketing of products using nanotechnologies;

- Engage with suppliers and/or business partners to encourage and stimulate their adoption of the Code and so assure its own ability to fulfil its Code commitments.

These were directed at the diverse fields of nanotechnologies, but a number of these principles could form guidance for the use of genome editing in industry. The second, fifth and sixth are of particular significance in the RRI aspects of relating to wider society.

\footnotetext{
${ }^{4}$ http://www.nanotechia.org/sites/default/files/files/20080501_The\%20Responsible\%20Nano\%20Cod e\%20Update\%20Annoucement.pdf accessed 4/12/2018.
} 
In 2012, the UK Technology Strategy Board developed a Responsible Innovation Framework that focussed on reflecting the challenges faced by innovation downstream of research. Tait (2017) described its aims "to consider the very different issues faced in more downstream innovation processes, the different sets of actors and stakeholders that will need to be involved and the need to make decisions in timescales that reflect the real challenges faced by companies in a competitive economic environment".

The Responsible Innovation Framework intended to take account of the needs of industry innovators as well as societal expectations. Part of this addressed elements of company governance (the governance part of the ESG criteria-Environmental, Social and Governance-for responsible companies, widely used in the field of corporate investment). This includes such factors as promoting sound practices in employment, avoiding undertaking business in countries that violate civil rights of their people etc. The project specific elements address the E and S criteria, for example promoting products that make a positive contribution to the environment and avoiding end uses that lead to social damage, and include the four EPSRC criteria mentioned earlier.

Tait (2017) then developed this framework further into a suggested Consolidated Responsible Innovation Framework. In this framework, she focuses on four key elements; societal, environmental, business practice and regulation. The societal element of this emphasises developing "products, processes and services designed to deliver societal benefits", minimizing risks and supporting equitable distribution of risks and benefits, and avoiding deliberate harm. In this framework, some innovations will require engagement but others will not. The environmental element supports the development of "products, processes and services that enhance and support the environment" and "considering lifecycle impacts including second and third order effects". Tait critiques some current understandings of RRI for having insufficient consideration to the societal benefits that may be gained from innovation and that should be taken into account.

It is difficult to know how far industry has embedded such codes into its working ethos and strategies. Tait (2017) suggests that industry actors were reluctant to engage with this attempt to developing a RRI framework due to perceptions of such processes politicising innovation initiatives in unhelpful ways. It may be the case that a company fears to do this in case it 'opens up a can of worms', attracting negative publicity, jeopardising their share price or their ability to win venture capital. This may be counterproductive, however. A House of Lords report on nanotechnologies applied to food noted the secrecy of companies to acknowledge the use of nanotechnologies in their food products (for fear of a negative public reaction if they did so), concluding that hiding something was more likely to precipitate negative reaction than being transparent (House of Lords 2010).

But for a company to introduce some form of RRI exercise into its strategy could pose a number of problems. First, at what point in the transition period should RRI be done, once the decision has been made to take it out of the lab and embark on the process leading to its ultimate production? Secondly, if the feedback from an RRI exercise turned out to be negative, is the company prepared to change what it intended to do, and accept some loss of its sunk costs of research? 
Thirdly, there are the prevailing values and power relations within the company at that point in time, perhaps coming down less to company values than to influential individuals in the management or board. Some could argue that RRI was exercising 'due diligence' in foresighting the likely market success of the projected product, to circumvent the risk that, if 'the market' was unprepared or potentially hostile, the whole project might founder. On the other hand, others might see RRI as introducing an element of uncertainty and delay into the trajectory of commercialisation, if the dominant voice in the company is the urgency to see the innovation come to market and secure a place among possible rivals, and to pay back some of the investment. In the latter view, the risk would be that a less fastidious company, or perhaps one working in a less regulated country, could corner the market in the meantime.

The assertion that there was no time to find out how a controversial product fitted with wider society would seem incompatible with responsible innovation. It might rather be argued that the time it might take to get the answer 'yes, go ahead with society's blessing' was an integral part of the process of translation, from which the organisation could go ahead with more confidence. An established plc with a portfolio of products should be able to cope with this process, but a venture capitalised start-up company with known rivals in the field, for which this is the only product, delay might be perceived as unacceptable.

Meijboom et al. (2006) identified a need for what they termed 'pro-active responsibility', in which the exercise of responsibility in innovation moves from something that is done because it is enforced externally, such as regulation, to an inner responsibility, expressing the person's or the company's own values and visions of a desirable future. In making this change, it then becomes important to make explicit the values that are driving a specific development. This in turn implies a need to be prepared to engage with and be responsive to other values.

The likelihood that a company embraces the concept of RRI is likely to depend on both internal and external factors. The level of uptake depends on the values and self-image of the company, and the prevailing internal reasons which influence why it behaves in particular ways. Key external factors are the degree of competition and the confidence that consumers would buy the product. This last point is particularly important for genome editing in food animals, because consumer acceptance in Europe is uncertain. Any company wishing to have a European market for the types of innovations highlighted in the previous section will need to take RRI seriously on board.

\section{Applying RRI to Genome Editing}

We now return to the two examples of animal genome editing cited in "Genome Editing in Livestock Animals" section above. These were chosen, not only because they are relatively close to market, but also in that they address livestock welfare issues in a production context. This, in part, is a conscious response to the widespread criticism of most genetically modified food crops, that they provided production advantages to farmers, but no tangible benefits to sceptical consumers. 
It remains to be seen, however, whether gene edited polled dairy cattle and PRRS resistant pigs will be viewed by veterinary surgeons and farmers as another method of producing the animals in more sustainable and welfare friendly ways, and whether consumers and retailers view the food products as acceptable. These practical cases are examples where RRI could play an important role. We now consider some of the pertinent issues which the application of RRI would need to address.

\section{Example 1: Polled Dairy Cattle}

It could be argued that this is a minor, even trivial, change to the physiology of the animal, with considerable welfare benefits. However, there is evidence to suggest that horns also have a role in thermoregulation and in self-grooming (Knierim et al. 2015).

The stated welfare motivation is that cows without horns can do less damage to each other and to their human carers. There appears to be conflicting evidence as to whether cows without horns are less aggressive than those with horns; those with horns appear to keep greater distances from each other (Knierim et al. 2015). The specific circumstances may also be important in identifying behavioural changes, e.g. whether the cows are housed or grazing, different effects on high ranking or low ranking cows, or young cows newly being introduced into the herd (Knierim et al. 2015). All these questions will arise whether the cows are polled as a result of genome editing, by physical removal of horns or natural polledness, but they serve to indicate the complexity of an issue which at first glance may appear simple.

The second welfare aspect is that concerns are raised about the methods used in current agricultural practice to remove their horns when they are calves. These usually involve cauterization or applications of caustic paste (Spurlock et al. 2014), processes that are both painful for the animals and unpleasant for the human operators of the process. Nonetheless, Cozzi et al. (2015) report that the practice is very common among dairy cattle in EU Member States, with $81 \%$ of the surveyed dairy farms using animals where horns have been removed. They found the practice is more common when cattle are loose housed rather than tethered. Ironically, an increased removal of horns may be a consequence of changing dairy production systems to improve welfare, by replacing tethering cows individually to loose housing, allowing them freedom of movement.

If polled dairy cows are a desirable aspiration, genome editing is only one of several ways of achieving this end, including selecting polled cows, cross-breeding, and using genetic markers to aid selection. Selecting polled cows for the next generation requires these animals to exist in order to be selected for the next generation. Polled dairy cows are rare and selection for these animals may compromise selection for other desirable characteristics. The extent to which other desirable traits are affected may vary with breed, for example Spurlock et al. (2014) calculated larger negative impacts for Holstein cattle than Jersey cattle.

Cross-breeding polled beef cattle with horned dairy cattle is possible, but mixing beef genes into dairy would have a severe impact on important characteristics such as milk yield. The process of breeding would also be slow because the polled variant 
is a recessive gene; both parents must carry it before the offspring are polled. Using genetic tests to identify cattle with the polled gene variant exist, for example in Australia, ${ }^{5}$ but a given genetic marker appears only to apply to some breeds but not others. The genetics of polledness appears to be more complex than previously thought (e.g. Wiedermar et al. 2014; Chen et al. 2017).

Based on the previous responses of public, media and retailers to GM foods in the late 1990s, the new application of genome editing to food animals could be seen as a potentially contentious area in the UK and the rest of Europe. From the industry point of view, in this example no transfer of genes across species is involved. All that has been done is to introduce a gene variant from one breed of cattle to another. Would the fact that it is not strictly transgenesis be a clinching argument for consumer acceptance, or would any genetic change be considered in the same vein as $\mathrm{GM}$, in the sense of 'fiddling around with genes'? Would a major retailer fear being targeted by aggressive NGO action if it 'stepped out of line' and became the first to market the dairy products of gene edited polled cattle?

Moreover, the arguments made above of the human and animal welfare benefits of polledness from an industry and production perspective may not be readily accepted by publics. While these may be obvious to those familiar with current agricultural practice, to most people outside it the practice of polling could come as a surprise, because of a general low level of public knowledge of current UK agricultural practices in general, and in this case the reality of working with livestock. Thus the offer of a 'technical fix' to an existing industry problem may appear less appealing than questioning polling altogether. For example, a perception that 'if cows have horns, it is unnatural or inhumane to remove them' might be significant. Another reaction of lay publics might be that an 'industrialised' dairy production system is unacceptable, and turn instead to non-dairy sources of 'milk' based around plant products. Last, but by no means least, is that for some people the overriding question is one of ethical principle, namely that it is considered unacceptable to use animals for food, or even for any human purposes at all.

There may therefore be quite different views on the acceptability of a genome editing application even motivated by welfare considerations. It would be important therefore to engage wider society in an RRI exercise, to bring out and discuss some of these issues. This might serve to bridge some of the gap between agricultural practice and the consumer, which might result in changes of both attitude and practice on either side. The fear on the part of industry of doing so should be set against the risk of a polarised and sensationalised confrontation via the media, like that which characterised much of the UK GM food debate.

\footnotetext{
5 https:/www.goodmeat.com.au/globalassets/goodmeat/animal-health-and-welfare/poll-gene-test.pdf accessed 1/12/18. However, the web page appears to date to 2013 and it is not clear as to the extent to which the markers are used in current practice.
} 


\section{Example 2: PRRS Resistance in Pigs}

The application of genome editing to introduce resistance to PRRS infection is argued by its proponents to be attractive from animal health and welfare perspectives, as well as from and economic point of view. How would this be received by publics?

In contrast to the polled cattle example, the welfare benefit of preventing pigs from contracting PRRS is less likely to be contested, as such, even though most people would be unlikely to have heard of the disease. If one accepts eating pig products at all, disease prevention would be seen as a humane response if we had the means to do so, but some might still be uncomfortable with the method. Would people eat pork from such pigs? Would the welfare of pigs weigh more in consumers' minds and hearts than the associations of genetic modification of their food? Would this be a breakthrough, in that here was an example of genetically altered food for a purpose that was seen as valid, or would the demand be for alternative solutions because of the pervasive stigma of GM, even though once again transgenesis is not involved.

Once again, an appropriate RRI engagement between the industry, stakeholders and publics could offer the hope of a more informed assessment on the part of UK citizens. For example, at first sight some might dismiss this application as a technical fix for a problem that is caused by large scale and intensive pig units. But discussion with industry could reveal a more nuanced understanding, that while large scale pig production may exacerbate the spread of PRRS, it would not eliminate a disease that is a potential threat to all types of pig unit, large and small, indoor and outdoor, etc. Again engagement might also widen the debate to include other factors, such as the tendency for the PRRS infection also to affect the pig's disease defence mechanism. This makes the pig more susceptible to other diseases, such as pneumonia, ${ }^{6}$ that are then treated with antibiotics. In an era where bacterial resistance to antibiotics has become a major policy concern, and reducing the use of antibiotics in food production a priority, avoiding these secondary infections becomes important. Thus what started out perhaps as a single question may encourage a reflection on wider issues.

\section{What Do These Examples Tell Us About RRI?}

A major underlying problem is the knowledge gap between the food we eat and the way it is produced. Whereas polled cattle are seen by the cognoscenti in the industry as a significant animal welfare improvement, and resistance to PRRS as highly desirable within the pig industry, there is a disconnection of such applications from wider society. Whether some of these are perceived to be welfare benefits by wider publics remain to be seen. Well-meaning applications of genome editing could fall foul of this disconnect. This may be a more serious issue than the potential impact

\footnotetext{
${ }^{6} \mathrm{http}: / / \mathrm{www}$.thepigsite.com/diseaseinfo/97/porcine-reproductive-respiratory-syndrome-prrs/accessed $1 / 12 / 18$.
} 
of adding genome editing technology itself. Without some form of RRI engagement, the focus on benefits that do not impact immediately on consumers may still not be solved.

One example of a thoughtful method of public engagement (Gremmen and Block 2016) was reported at the Eursafe meeting in 2017. Here, publics were asked to engage with a range of different methods of dealing with male chicks of egg laying strains. As the male chicks currently have no value in food production, the current practice is to kill them at hatching. A sample of Dutch publics were invited to comment on a range of alternative methods of removing male chick, including taking biopsies to identify male eggs and using genome editing to produce green fluorescence in male eggs which could then be removed before hatching. In this small sample, the public preferred genome editing to biopsies, but found the current method of killing make chicks at birth the most preferable. While too much should not be made of a limited example, it illustrates the ability of those publics to engage with a difficult aspect of egg production and to weigh up alternative management methods.

Some evidence of the types of genome editing applications which might elicit a positive public response can be gleaned from an exercise conducted by Hopkins Van Mil on behalf of the UK Royal Society (Van Mil et al. 2017). Applications for reduced antibiotic use, greenhouse gas emissions, and reduced possibility of transmitting zoonotic diseases were all deemed acceptable. Concern for the environment and animal welfare were important, and use of genome editing for increasing productivity was rejected. Specialist uses such as preventing the extinction of a species or producing milk suitable for babies were affirmed. A major pre-occupation was to ensure genome editing was used to address inequality (in all its manifestations). Therefore, questions were raised about who owns the technology, who gets rich from its use and can it be used to unfairly obtain monopoly power?

This specific dialogue process could be interpreted as giving a rather positive response to applications of genome editing, given some caveats. However, history reminds us that in the early stages of development of GM crops, the UK Biotechnology and Biological Sciences Research Council (BBSRC) held a public consensus conference. This conference produced similar responses, i.e. no in-principle objections, but highlighting the need for certain aspects to be paid attention to e.g. the impact on Lower Income Countries (Purdue 1999). What might be the lesson from this earlier exercise, apart from the fact that the results appear to have been ignored by policy makers? Does this suggest that it is too early to take the Royal Society results at face value, and that care needs to be taken in development? A further caveat about RRI engagement comes, ironically, from the field of regulation and law. The European Court of Justice was asked by a French farmers' organisation to judge on whether an application of genome editing should fall within the scope of the existing EU Directive on genetically modified organisms (Directive 2001/18/ EC). One of the crucial arguments was whether genome editing resembled a more precise form of the crop modifications made by random mutagenesis, which fell outside the Directive. To the incredulity of many scientists, the court judged that these genome edited organisms were to be considered as subject to the full range of testing and regulation according to the EC Directive, as if they were transgenic, but that 
the early untested products of random mutagenesis were de facto considered to have been immune from such risks.

The problem for RRI is less the judgement and its implications, than the fact that this consideration was made without an engagement with publics. The decision by the European Court of Justice on effectively side-stepped any processes of wider societal engagement. Has this reduced RRI of genome editing in food into a matter of legal judgement, which is as far removed from the public as decisions over GM food were in the mid-1990s?

To those keen to press ahead with a new technology, the regulatory process can represent a delay in the innovation process. But done properly, regulation represents the formal statutory public responsibility of a new technology, and its governance. Regulation sets bounds to what can be done, who can do it and under what conditions can things be done. But if there has been no discussion with the public, this could be argued to be a case where regulation has been socially premature, and not done on behalf of the society.

\section{Conclusions}

In this paper we have explored the tensions between rapidity of genome editing research and the slower, more reflective pace required to undertake effective RRI processes. In particular, we have examined the prospects of extending the RRI framework from the research arena, to industry and the commercialisation of the outputs of genome editing.

We have briefly reviewed the principal features of RRI, with four core principles of anticipation, reflexivity, inclusion and responsiveness. It was noted that in an EU and UK context, RRI is mainly considered in relation to research, and less to application in innovation. We then summarised the disruptive advent of genome editing techniques and especially of the CRISPR method, whose ease of use, cheapness, specificity and efficiency have led to an avalanche of applications in a wide range of fields. Notable amongst these is making direct genetic changes to food animals for the first time, in cattle and pigs. In contrast to 'conventional' genetic modification, most of these are focussing on traits that do not require transfer of genes from one species to another, and are deemed to provide welfare benefits to the animals.

We suggest that the speed, the breadth of scope and the disruptive potential of genome editing together present a serious challenge to the very concept of responsible research and innovation, because to engage with publics and other stakeholders on novel and disruptive technologies takes time. Moreover, engagement exercises only reach a small number of people. Mass media and social media have much wider impact, but may then be subject to the tropes and biases of these media, resulting in less well informed and reflexive public debate. In the case of nanotechnologies engagements were too early and the questions are too broad. In the case of CRISPR research the 'genie' might well be out of the bottle.

We suggest that it is in the application stage of genome editing that RRI has a crucial role to perform. This would entail putting the ' $I$ ' back into the RR, and focus 
on encouraging companies to take RRI on board. A number of examples are cited including the UK Technology Strategy Board's Responsible Innovation Framework.

We applied RRI thinking to our two example applications of genome editing to livestock and highlighted some of the main issues which would need to be taken into account. We found that a key aspect is the knowledge gap of publics of current practices in livestock agriculture, which could lead to unexpected outcomes from public consultations. RRI has an important role therefore not only in considering the innovation but understanding it in the context of current agricultural processes. A useful way of examining such questions is to consider the range of options that could be available to address the issue, rather than just the innovation under question. Furthermore, as applications of biotechnology are subject to regulations, it may be the case that the final arbiter is the legal profession. This has effectively been the case in the EU due to the judicial review asserting that genome edited products should be treated under GMO legislation, making it unlikely that they will be economic to develop.

\section{Compliance with Ethical Standards}

Conflict of interest The authors declare that they have no conflict of interest.

Open Access This article is distributed under the terms of the Creative Commons Attribution 4.0 International License (http://creativecommons.org/licenses/by/4.0/), which permits unrestricted use, distribution, and reproduction in any medium, provided you give appropriate credit to the original author(s) and the source, provide a link to the Creative Commons license, and indicate if changes were made.

\section{References}

Asveld, L., Ganzevles, J., \& Osseweijer, P. (2015). Trustworthiness and responsible research and innovation: The case of the bio-economy. Journal of Agricultural and Environmental Ethics, 28(3), 571-588.

Bastiaansen, J. W. H., Bovenhuis, H., Groenen, M. A. M., Megens, H.-J., \& Mulder, H. A. (2018). The impact of genome editing on the introduction of monogenic traits in livestock. Genetics Selection Evolution, 50, 18.

Bhattachary, D., Stockley, R., \& Hunter, A. (2008). Nanotechnology for healthcare. Prepared for: Engineering and Physical Sciences Research Council, July 2008, British Market Research Bureau BMRB/08/4510-7290.

Bruce, D., \& Bruce, A. (1998). Engineering genesis, 1998. London: Earthscan.

Burget, M., Bardone, E., \& Pedasto, M. (2017). Definitions and conceptual dimensions of responsible research and innovation: A literature review. Science and Engineering Ethics, 23(1), 1-19.

Burkard, C., Lillico, S. G., Redi, E., Jackson, B., Mileham, A. J., Ait-Ali, T., et al. (2017). Precision engineering for PRRSV resistance in pigs: macrophages from genome edited pigs lacking CD163 SRC5 domain are fully resistant to both PRRSV genotypes while maintaining biological function. PLoSpathog, 13, e1006206.

Carlson, D. F., Lancto, C. A., Zang, B., Kim, E. S., Walton, M., Oldeschulte, D., et al. (2016). Production of hornless dairy cattle from genome edited cell lines. Nature Biotechnology, 34, 479-481.

Chen, S. Y., Liu, L., Fu, M., Zhang, G. W., Yi, J., et al. (2017). Simultaneous introgression of three POLLED mutations into a synthetic breed of Chinese cattle. PLOS ONE, 12(10), e0186862.

Chneiweiss, H., et al. (2017). Fostering responsible research with genome editing technologies: A European perspective. Transgenic Research, 26, 709-713.

COGEM. (2017). Report on the symposium 'gene editing in animals', 19 \& 20th Oct. 2017 in Amsterdam. Available at https://www.cogem.net/index.cfm/en/publications/publication/event-report-gene-edite 
d-animals-applications-and-implications?order=relevance $\& \mathrm{q}=\&$ category $=$ event-reports- $1 \&$ from $=30$ 09-1998\&to=24-11-2018\&sc=fullcontent. Accessed July 5, 2019.

Cozzi, G., Gottardo, F., Brscic, M., Contiero, B., Irrgang, N., et al. (2015). Dehorning of cattle in the EU Member States: A quantitative survey of current practices. Livestock Science, 179, 4-11.

Eriksson, S., Jonas, E., Rydhmer, L., \& Röcklingsberg, H. (2018). Invited review: Breeding and ethical perspectives on genetically modified and genome edited cattle. Journal of Dairy Science, 101(1), 1-17.

Gavelin, K., Wilson, R., \& Doubleday, R. (2007). Democratic technologies? The final report of the Nanotechnology Engagement Group (NEG). London: Involve.

Genus. (2015). Announcement information digest. Genus tackles major pig disease with breakthrough technology. http://na.pic.com/Uploads/Files/News/PRRS\%20Announcement\%20Information\%20Dig est\%20and\%20FAQ\%20-\%20FINAL\%2011[1].12[1].15[1].pdf. Accessed December 1, 2018.

Gremmen, B., \& Block, V. (2016). The lesser of two evils? The killing of day-old male chicks in the Dutch egg sector. In I. A. S. Olsson, S. M. Araújo, \& M. F. Vieira (Eds.), Food futures: Ethics, science and culture (pp. 72-75). Wageningen: Wageningen Publishers.

House of Lords. (2010). Nanotechnologies and food, science and technology committee, 1st report of session 2009-10, paras 7.15 to 7.19. London: The Stationery Office Limited.

Hoyos-Flight, M., Brady, E., Sang, H., \& Whitelaw, B. (2017). Genome editing and the Future of Farming meeting report. Transgenic Research, 26(2), 319-321.

Knierim, U., Irrang, N., \& Roth, B. A. (2015). To be or not to be horned-Consequences in cattle. Livestock Science, 179, 29-37.

Knoppers, B. M., Thorogood, A., \& Chadwick, R. (2013). The human genome organisation: Towards nextgeneration ethics. Genome Medicine, 5, 38.

Meijboom, F. C. B., Visak, T., \& Brom, F. W. A. (2006). From trust to trustworthiness: Why information is not enough in the food sector. Journal of Agricultural and Environmental Ethics, 19, 429-442.

Mitcham, C., \& von Schomberg, R. (2000). The ethic of scientists and engineers: from occupational role responsibility to public co-responsibility. In P. Kroes \& A. Meijers (Eds.), The empirical turn in the philosophy of technology. Research in philosophy and technology (Vol. 20). Amsterdam: JAI Press.

O’Neill, O. (2018). Linking trust to trustworthiness. International Journal of Philosophical Studies, 26(2), 293-300.

Pellé, S. (2016). Process, outcomes, virtues: The normative strategies of responsible research and innovation and the challenges of moral pluralism. Journal of Responsible Innovation, 3(3), 233-254.

Proudfoot, C., Carlson, D. F., Huddart, R., Long, C. R., Pryor, J. H., King, T. J., et al. (2015). Genome edited sheep and cattle. Transgenic Research, 24, 147-153.

Purdue, D. (1999). Experiments in the governance of biotechnology: A case study of the UK Consensus Conference. New Genetics and Society, 18(1), 79-99.

Ribeiro, B. E., Smith, R. D. J., \& Millar, K. (2017). A mobilising concept? Unpacking academic representations of responsible research and innovation. Science and Engineering Ethics, 23, 81-103.

Ruan, J., Xu, J., Chen-Tsai, R. Y., \& Li, K. (2017). Genome editing in livestock: Are we ready for a revolution in animal breeding industry? Transgenic Research, 26, 715-726.

Spurlock, D. M., Stock, M. L., \& Coetzee, J. F. (2014). The impact of 3 strategies for incorporating polled genetics into a dairy cattle breeding programme on the overall herd genetic merit. Journal of Dairy Science, 97, 5265-5274.

Stilgoe, J., Owen, R., \& Macnaghten, P. (2013). Developing a framework for responsible innovation. Research Policy, 42, 1568-1580.

Tait, J. (2017). From responsible research to responsible innovation: Challenges in implementation. Engineering Biology, 1(1), 1-5.

Van Mil, A., Hopkins, H., \& Kinsella, S. (2017). Potential uses for genetic technologies: Dialogue and engagement research conducted on behalf of the Royal Society. Available at https://royalsociety.org/ / media/policy/projects/gene-tech/genetic-technologies-public-dialogue-hvm-full-report.pdf. Accessed November 29, 2018.

von Schomberg, R. (2013). A vision of responsible research and innovation. In R. Owen, M. Heintz, \& J. Bessant (Eds.), Responsible innovation. London: Wiley.

Whitworth, K. M., Rowland, R. R., Ewen, C. L., Trible, B. R., Kerrigan, M. A., Cino-Ozuma, A. G., et al. (2016). Gene-edited pigs are protected from porcine reproductive and respiratory virus. Nature Biotechnology, 34, 20-22.

Wiedermar, N., Tetens, J., Jagannathan, V., Menoud, A., Newenschwander, S., Bruggmann, R., et al. (2014). Independent polled mutations leading to complex gene expression differences in cattle. PLoS ONE, 9(3), e93435. 
Wu, H., Wang, Y., Zhang, Y., Yang, M., Lv, J., Liu, J., et al. (2015). TALE nickase-mediated SP110 knockin endows cattle with increased resistance to tuberculosis. Proceedings of the National Academy of Sciences of the United States of America, 112, E1530-E1539.

Publisher's Note Springer Nature remains neutral with regard to jurisdictional claims in published maps and institutional affiliations. 